\title{
CRITÉRIOS DE DESEMPENHO DOS PAÍSES COMPRADORES BASEADO NAS EXPORTAÇÕES BRASILEIRAS: UMA PROPOSTA DE ANÁLISE
}

\author{
Performance Criteria of the Purchasing Countries Based \\ on Brazilian Exports: an Analysis Proposal
}

Recebido em 24.08.09 / Aceito em 01.03.10

\begin{abstract}
Tonia Magali Moraes Brum ${ }^{1}$, Ana Elizabeth Moiseichyk ${ }^{2}$ e Cristiano Henrique Antonelli da Veiga ${ }^{3}$
\end{abstract}

\begin{abstract}
Resumo
O objetivo deste artigo foi o de estabelecer critérios que possibilitem caracterizar o desempenho dos países compradores, baseando-se nos resultados das exportações brasileiras. Para realizar o estudo, o segmento utilizado foi o de moda praia feminina, investigando qual é a sua importância em termos de mercado para o Brasil. Como resultado, estabeleceu-se um perfil baseado em sete critérios de análise. Para tanto, o estudo baseou-se em dados secundários quantitativos e oficiais, disponibilizados pelo Ministério do Desenvolvimento, Indústria e Comércio Exterior do Brasil, do período entre 2005 até 2009. Constatou-se que, em 2009, apenas os 10 principais importadores da moda praia brasileira totalizaram $73,3 \%$ das exportações, sendo 79,3\% em três estados do país. O primeiro semestre do ano concentrou $83,3 \%$ da quantidade exportada, e o preço mediano apresentou crescimentos consecutivos. Com base nos critérios estabelecidos, estruturou-se uma tabela com os 100 principais países compradores e o seu perfil, concluindo-se que os Estados Unidos é o principal expoente, com 36,3\% da quantidade exportada, valor médio US $\$ 7.75$ FOB, perfil comprador habitual, performance de compra em declínio, tendência de preço variável e valor agregado baixo.
\end{abstract}

Palavras-chave: Exportação brasileira; Moda praia feminina; Países compradores; Exportação.

1 Doutora em Administração. Professora Adjunta da Universidade Federal de Santa Maria (UFSM), lotada no Departamento de Administração, campus Palmeira das Missões. E-mail: toniabrum@hotmail.com

2 Doutora em Engenharia da Produção. Professora Adjunta da UFSM, lotada no Departamento de Administração, campus Palmeira das Missões. E-mail: anamoiseichyk@hotmail.com

3 Mestre em Engenharia da Produção. Professor Assistente da UFSM, lotado no Departamento de Administração, campus Palmeira das Missões. E-mail: chadaveiga@smail.ufsm.br 


\begin{abstract}
The aim of this paper was to establish criteria to characterize purchasing countries performance based on the results of Brazilian exports. For the study, the segment was used beachwear women, investigating what is its importance in terms of market for Brazil and as a result has established a profile based on seven criteria. To this end, the study was based on secondary quantitative data and officers provided by the Ministry of Development, Industry and Foreign Trade of Brazil during the period from 2005 until 2009. It was found that in 2009, only the 10 top Brazilian's beachwear importers totaled $73.3 \%$ of exports, with $79.3 \%$ in three states in the country, the first half of the year concentrated $83.3 \%$ of the quantity exported and the price median had consecutive growth. Based on the criteria set was structured with a table with 100 buyer countries and their profile. The United States is the leading exponent with $36.3 \%$ of the quantity exported, the average U.S. \$ 7.75 FOB, Profile usual buyers, purchasing performance declining, price trend variable and low added value.
\end{abstract}

Keywords: Brazilian exportation; Beachwear; Importers players; Exportation.

\title{
1 Introdução
}

A literatura em comércio exterior (VAZQUEZ, 2007; FARO; FARO, 2007; MAIA, 2008, APRENDENDO A EXPORTAR, 2010) sugere, tradicionalmente, que o empreendedor faça uma pesquisa inicial para verificar o perfil e o comportamento dos mercados internacionais antes de iniciar o processo de internacionalização de seus produtos ou serviços, mas, raramente, apresentam uma proposta de análise de dados quantitativos que possam propiciar subsídios concretos preliminares a uma tomada de decisão.

De acordo com Ferreira e Moreira (2008), com o aumento significativo do volume e velocidade com que se conseguem dados, nas mais diferentes fontes e nas mais variadas formas, provoca, para as organizações, certa dificuldade no adequado tratamento, de forma a possibilitar a sua utilização no apoio à decisão. Os autores destacam que muitas organizações dedicam considerável esforço no ato de dominar a transação de dados e pouco em transformá-los em informação, produzindo, neste caso, pouco conhecimento. A transformação dessas informações em conhecimento que possa ser aplicado e sistematizado, possibilitando no auxílio à definição, mudanças ou monitoramento das estratégias de uma organização, é o que muitos pesquisadores buscam identificar.

Diante do exposto, propiciar a transformação de dados quantitativos secundários em conhecimento aplicado de forma a caracterizar o processo de exportação de moda praia feminina das empresas brasileiras foi o que objetivou este estudo, possibilitando debater o comportamento dos países importadores deste segmento empresarial ao longo de cinco anos, e determinar o seu perfil importador. Do ponto de vista metodológico, quanto aos fins, a pesquisa caracteriza-se como descritiva; quanto aos procedimentos, bibliográfica e documental, e enquanto à análise do problema, quantitativa baseada nas exportações das empresas brasileiras.

As partes que compõem este artigo são: os negócios internacionais e a inteligência competitiva, a inovação no mercado da moda e a caracterização da moda praia. Como referencial teórico, os critérios metodológicos da pesquisa, subdivididos em dois aspectos: o primeiro delimita as variáveis e o período do estudo, e o segundo estabelece os critérios da análise quantitativa de desempenho dos países compradores, conforme o desempenho exportador brasileiro. Em seguida, são apresentados o desempenho exportador brasileiro de têxteis e confeccionados, 
os resultados das exportações de moda praia feminina e a tabela que estabelece o perfil dos 100 primeiros países importadores. Para concluir o estudo, são realizadas as considerações finais e apresentadas as referências utilizadas.

\section{Estudos teóricos}

\subsection{Negócios internacionais e inteligência competitiva}

O monitoramento do ambiente externo à organização é fundamental para permitir a constante reavaliação de seu posicionamento competitivo e a estruturação de possíveis reconfigurações de seus processos e produtos. No âmbito de negócios internacionais e gestão internacional, o uso da análise comparativa dos agentes operantes em determinado segmento de mercado possibilita verificar o desempenho do setor e a busca de superação dos desafios enfrentados (FARO; FARO, 2007).

Ao analisar estudos de casos de negócios internacionais de pequenas e médias empresas brasileiras (DA ROCHA; DE MELO, 2006) e de gestão internacional (GUEDES, 2008) verifica-se que a característica comum é fato de que as decisões estratégicas e práticas tanto de empresas multinacionais quanto de pequeno porte contemplarem múltiplos níveis de análise (global, internacional, nacional, interorganizacional e intraorganizacional). Estes níveis refletem a complexidade e interdependências referentes ao amplo mundo dos negócios internacionais, que não são tão observadas em outras áreas, independente do porte das empresas.

Paralelamente ao debate sobre a constituição e diferenciação dos campos de gestão internacional e negócios internacionais, os pesquisadores dessas áreas enfrentam outro desafio: entender o fenômeno do comportamento dos mercados internacionais. Guedes (2008) salienta que independente de conceitos, a globalização criou ambientes mais complexos que exigem análises fundamentadas em uma noção mais ampla dos negócios internacionais que implica na análise do comportamento dos players internacionais.

Gomes e Braga (2001) salientam que, a capacidade de uma organização em desenvolver mecanismos que possibilitem a previsão das mudanças no ambiente externo pode representar, em boa medida, a sua sustentabilidade, posto que tal capacidade permite que ela reavalie, frequentemente, seus procedimentos internos e, eventualmente, realize os ajustes de posicionamento frente às novas condições e nuanças do mercado.

Para se realizar o processo de mapeamento do ambiente, dentre os diversos elementos sugeridos por Castro e Abreu (2006), um pode ser destacado: o ato de compreensão e percepção de que os outros atores estão realizando e do comportamento do ambiente em que se situam, permitindo ao tomador de decisão avaliar a adequação de sua interpretação pessoal com os resultados do ambiente real.

É nesse sentido que o uso de técnicas de inteligência competitiva pode ser definido como processo contínuo e sistemático de coleta, gestão, análise e disseminação de informações estratégicas para o processo decisório de uma organização, tanto em seu mercado doméstico como internacional (MILLER, 2002).

Garrido (2007) indica que, embora bastante investigada, a questão da relação entre orientação para o mercado e performance possibilitam focos para diferentes estratégias. Assim, o autor examina empiricamente o papel dos tipos de estratégia de negócio como potenciais moderadores da relação orientação para mercado externo, conforme ilustra a figura 1. 


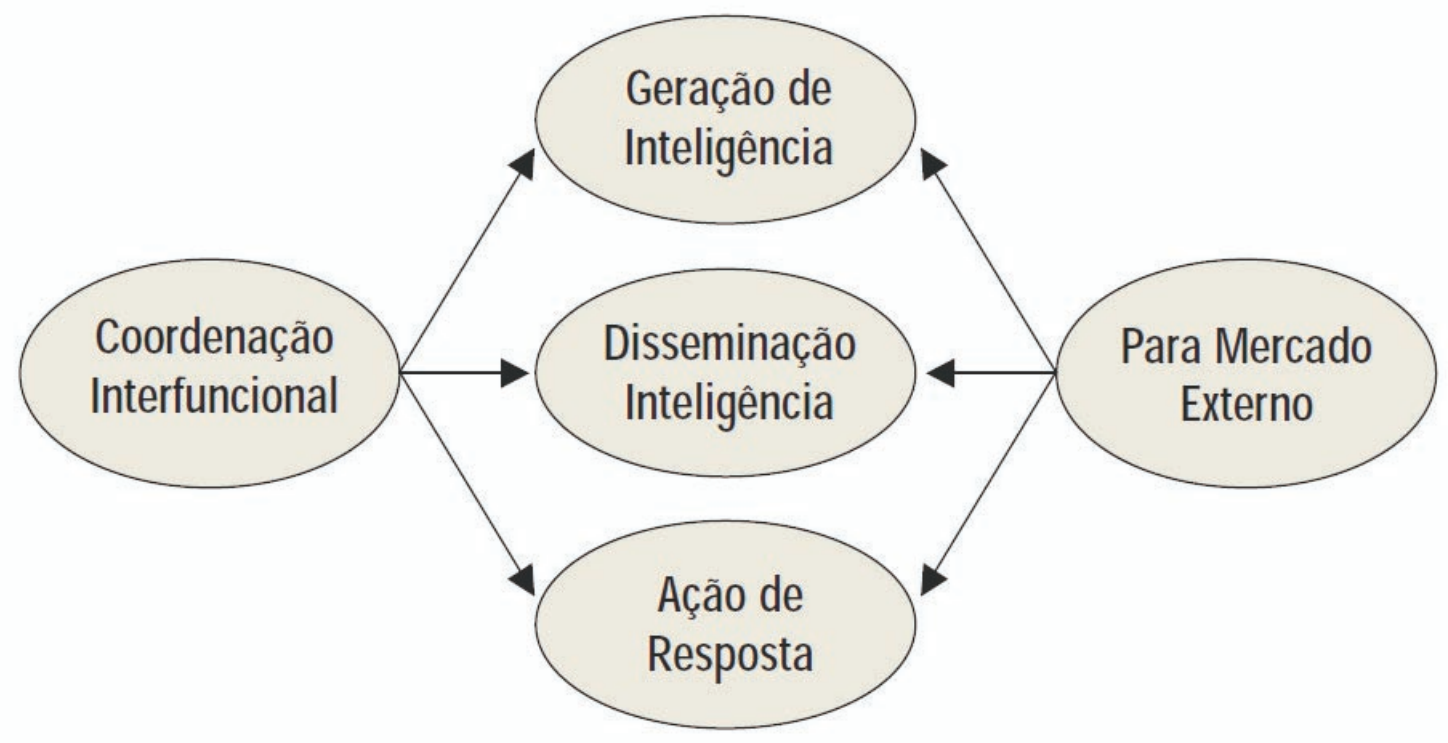

Figura 1 - Modelo sintético para orientação para o mercado Fonte: Garrido (2007, p. 125).

No Brasil, segundo Garrido (2007), os estudos sobre orientação para mercado, em ambiente doméstico, já se encontram em fase madura, mas praticamente inexistem em ambientes internacionais. Como evidenciam os seus estudos, a geração de inteligência exportadora transpassa pela investigação inicial de tendências e comportamento de consumo no mercado internacional como fatores válidos para estudos nesta área.

Em consonância com este pensamento, Khauaja e Henzo (2007) demonstram que, além do estudo da inteligência exportadora, existem outros fatores que dificultam o processo de internacionalização brasileiro, tais como: os problemas de infraestrutura, a tradição de economia fechada e o mercado interno forte.

Para Vazquez (2007), outros entraves são identificados como limitadores desta prática, identificados como gargalos burocráticos. A dificuldade de acesso ao financiamento e a falta de uma política governamental consistente e eficaz para incentivar a internacionalização também contribuem para limitar a motivação empresarial das empresas brasileiras.

\subsection{Inovação}

De acordo com Lindon (2000), a novidade de um produto é determinada pela percepção que têm dele os indivíduos quando confrontados com essa inovação. A inovação será qualquer coisa vista como sendo nova pelo eventual utilizador, e sua adoção provocará modificação significativa no comportamento do comprador.

Como visto, a forma de inovar é bastante flexível e depende, principalmente, da sua aplicabilidade. De maneira sucinta, inovação é a exploração com sucesso de novas ideias. Dentre as várias possibilidades de inovar, aquelas que se referem a inovações de produto ou de processo são conhecidas como inovações tecnológicas (INSTITUTO INOVAÇÃO, 2008).

Outros tipos de inovações podem se relacionar a novos mercados, novos processos, novos modelos de negócio e métodos organizacionais ou, até mesmo, novas fontes de suprimentos. De acordo com Drucker (1995 apud BESSANT; TIDD, 2009, p. 27), "a inovação é a 
ferramenta-chave dos gestores, o meio pelo qual exploram a mudança como uma oportunidade para um negócio ou serviço diferente".

No entanto, inovação não pode ser confundida com invenção. Ter uma ideia brilhante não basta para realizar uma inovação em uma empresa, é preciso incorporar um valor ao produto ou processo de fabricação (NICOLSKY, 2007).

Geralmente, ao falar de inovação, o que vem à cabeça é um exemplo de inovação radical, com quebra de paradigma tecnológico, trazendo uma novidade absoluta, revolucionária, como, por exemplo, a invenção do computador. No entanto, a inovação incremental, resultado da atividade paciente e exaustiva de tentar melhorar aquilo que já existe, também merece ser lembrada. O uso da inovação incremental queima etapas, posicionando a empresa num determinado mercado, sem passar pela "reinvenção da roda", faz-se em chão de fábrica, a partir do trabalho sobre o que já existe, economizando tempo e recursos escassos. Surge para resolver problemas práticos, como diminuir custos ou acelerar um processo, produzir com maior eficiência, adaptar um produto a novas necessidades e desejos do consumidor (NICOLSKY, 2006).

Outro aspecto que deve ser observado, de acordo com o Instituto Inovação (2008), é que, frequentemente, há uma confusão entre inovação e processos de melhoria contínua. Para que uma inovação seja caracterizada como tal, é necessário que seja causado um impacto significativo na estrutura de preços, na receita da empresa, na participação de mercado etc. Já as melhorias contínuas, normalmente, não são capazes de criar vantagens competitivas de médio e longo prazo, mas servem para manter a competitividade dos produtos em termos de custo.

De acordo com o Instituto Inovação (2008), as inovações são importantes porque além da capacidade de agregar valor aos produtos e serviços de uma empresa, diferenciando-a do ambiente competitivo, elas permitem que as empresas acessem novos conhecimentos, novos mercados, realizem novas parcerias, aumentem o valor de suas marcas e, consequentemente, aumentem suas receitas.

Percebe-se, assim, que as inovações são capazes de gerar vantagens competitivas em médio e longo prazo, tornando-se fator essencial para a sustentabilidade das empresas e dos países no futuro. Obviamente os benefícios da inovação não se limitam às empresas. Para os países e regiões, as inovações possibilitam além do acesso ao mundo globalizado, o aumento do nível de emprego e renda (INSTITUTO INOVAÇÃO, 2008).

Atualmente, no Brasil, de acordo com Agência Brasileira de Desenvolvimento Industrial (ABDI, 2009), a inovação e o investimento são considerados os principais vetores do desenvolvimento industrial e, por isso, são partes integrantes das medidas da Política de Desenvolvimento Produtivo (PDP) e do Plano 2007-2010 - Ciência, Tecnologia e Inovação para o Desenvolvimento Nacional que se somam às regulamentações na área de inovação tecnológica (Lei n.. 11.196, de 21/11/2005 - Lei do Bem - e Lei n. 10.973, de 02/12/2004 - Lei de Inovação).

Em estudo realizado por Maffini Gomes e Kruglianskas (2010) em empresas brasileiras, demonstrou-se que os principais fatores que influenciam o desempenho inovador de uma empresa são: i) a inovação em produtos (analisada a partir do desempenho no mercado e da competitividade no mercado); ii) a inovação em processos (analisada através da qualidade dos processos empresariais) e iii) a capacidade inovativa (analisada pela competência tecnológica da empresa).

Especificamente no segmento moda praia, como na moda em geral, segundo Galvão (2002), a principal inovação está na evolução têxtil e nos materiais de alta tecnologia. 
De acordo com Marques (2004), os tecidos com inovações têxteis começaram a surgir cada vez mais rapidamente, através dos avanços da indústria têxtil, da fibra Lycra ${ }^{\circledR}$, do corte a laser e do tecido hightech com proteção de raios ultravioletas, há ainda o uso de materiais especiais que secam rapidamente devido a sua composição de fibras tecnológicas, outros que garantem proteção bacteriológica, evitando a proliferação de bactérias causadoras de odores, materiais "inteligentes", que respondem a estímulos ambientais, entre outras inovações.

No entanto, o design também vem se tornando muito importante para a diferenciação dos produtos, pois pode agregar valor através da redução dos itens referentes à formação do preço, através da economia de água e energia, redução da matéria-prima, racionalização da produção e otimização do processo, além do aumento da qualidade e dos atributos valorizados pelos consumidores, como desempenho e aparência (MARQUES, 2004).

Segundo Neves (2000, p. 5), o atual cenário de acirrada competição exige adaptáveis mudanças estruturais, conjunturais, flexíveis e produtivas: "É necessário que as empresas se preparem para conquistar 'nichos' de mercado onde as inovações tecnológicas, o design e a diferenciação dos produtos sejam fatores predominantes".

O mercado da moda é muito dinâmico, especialmente, porque o consumidor não se satisfaz com apenas quatro coleções por ano. Ele quer ver novidades semanalmente na loja de sua preferência. Sente-se atraído primeiramente pelo visual, em seguida experimenta a roupa e só então pergunta o preço. Para atender a este comportamento do consumidor, conforme Rodrigues Filho (apud IEL-FIEMG, 2008), o setor do vestuário necessita de muita competência para reagir rapidamente às mudanças, e as empresas são obrigadas a inovar constantemente na forma dos produtos, nas cores e nas texturas dos tecidos.

A partir do exposto, pode-se afirmar que desenvolver produtos de moda significa muito mais que a atribuição de uma etiqueta com o nome de uma marca importante, envolve a oferta de um diferencial (inovação) para o consumidor. Isso pode exigir inovação em mais de uma etapa do processo desde a elaboração de um conceito de coleção, passando pelo planejamento e, por fim, pelo desenvolvimento. Também itens como estilo, custos, infraestrutura industrial, disponibilidade de materiais, forma e cores precisam ser cuidadosamente analisados (MARQUES, 2004).

\subsection{Moda praia}

O traje de banho denominado biquíni surgiu, de acordo com Garcia (2010), em contra posição a série de testes atômicos realizados pelos Estados Unidos no pequeno atol de Bikini, localizado no Pacífico, sendo seu conceito desenvolvido pelo estilista francês Louis Réard. Descrito, inicialmente, pelos jornais da época, como "quatro triângulos de nada", o biquíni não obteve uma aceitação imediata pela população.

Do primeiro modelo, todo em algodão, com estamparia imitando a página de um jornal, se comparado aos modelos atuais, apresenta características diferentes em sua modelagem, estamparia e, principalmente, em tecidos. Conforme Feghali, Dwyer (2004), atualmente esta nova perspectiva está vinculada à incorporação no parque fabril brasileiro de máquinas ultramodernas que possibilitam acabamentos inovadores, definição e produção de novas cores, além de linhas de costuras e bordados que garantem a padronização da qualidade dos produtos.

Essas inovações, tanto de materiais quanto de modelagens e estilos, propiciam uma mudança da história da indústria de têxtil e de confecções ao longo dos últimos anos. Diante dessas novas tecnologias industriais, os tecidos atualmente utilizados para a confecção da moda 
praia possuem conceitos tecnológicos que possibilitam a secagem rápida, impedindo a proliferação de bactérias e protegendo a pele contra os raios ultravioletas.

Nos anos 2000, verificaram-se algumas das principais inovações com lançamentos de materiais têxteis para este segmento, dentre eles se destacou a tecnologia do Lycra® Xtra Life, que dá uma maior longevidade ao fio do tecido e permite conservar as formas de biquínis, maiôs e sungas até três vezes mais que o tradicional elastano, utilizado nos anos de 1990. Uma nova tendência apontada por Borielo (2010) está centrada no uso de sofisticados acessórios, que misturam o rústico, como cordas e macramês, chegando inclusive ao uso de ouro e outras pedras preciosas que propiciam brilhos sofisticados às peças.

O Brasil, por ser um país continental com uma costa marítima favorecida pelo clima e com mais de 7 mil quilômetros de praias, sem contar os milhares de lagos, rios, clubes e parques aquáticos existentes no interior do país e com a mudança da sua cultura nos anos de 1980, conforme Manequim (2010), voltada para a valorização do corpo, encontrou um campo fértil para o desenvolvimento comercial deste segmento empresarial.

Considerando o mercado de moda praia como uma atividade de negócio que, de acordo com Ferreirinha (apud BORIELO, 2010), iniciou no mundo a, aproximadamente, 30 anos e, no Brasil, está se consolidando nos últimos 20 anos devido a diversos fatores internos que possibilitaram a profissionalização da atividade e do fortalecimento do segmento de turismo de praia com a democratização do acesso da classe média, além do uso de estratégias emocionais bem planejadas para envolver o público, bem como a busca de novos mercados internacionais que propiciaram um incremento tecnológico no desenvolvimento, produção, criação e comercialização deste tipo de peça do vestuário.

De acordo com Feghali e Dwyer (2004, p. 15), “a moda é um negócio que gira milhões de dólares e por esta razão a maior parte das grifes fazem suas coleções com base em uma ou mais tendências dos grandes criadores". Com a globalização, a possibilidade de erros são menores devido ao fato de as coleções estarem num alinhamento muito semelhantes. As mesmas autoras salientam que profissionais desta área costumam realizar viagens técnicas internacionais, geralmente, duas vezes ao ano, entre os meses de abril e maio, para conhecer a moda verão, e setembro e outubro para ver a tendência da moda inverno que servirá de base para as coleções dos anos seguintes.

Neste viés, a indústria nacional tem tentado insistentemente associar a imagem do Brasil aos produtos de moda praia fabricados no país. As empresas, das grandes até as pequenas, têm se esforçado para conquistar espaço no mercado internacional, conforme Oliveira (2006), utilizando-se da estratégia de participação nas principais feiras do segmento (nacional e internacional).

\section{Metodologia}

\subsection{Delimitação, delineamento e técnicas de coleta de dados}

O estudo das exportações brasileiras de determinado setor empresarial pode ser caracterizado pela produção de conhecimento do geral para o particular, tratando-se do emprego do método dedutivo, essencialmente baseado em dados quantitativos, com nível de análise exploratória, do tipo descritiva que, conforme Stevenson (1981, p. 6), "envolve a organização e a sumarização dos dados", apoiada por investigação de dados contínuos secundários (análise documental) disponibilizados por meio do Portal Aliceweb da Secretaria de Comércio Exterior - (SECEX, 2010), órgão do Ministério do Desenvolvimento, Indústria e Comércio Exterior do Brasil. 
A documentação temática, na perspectiva de Severino (2002), possibilita a coleta de elementos relevantes para a realização de um trabalho em particular e em uma determinada área, que, neste caso, é a investigação do perfil dos países importadores de moda praia em relação à exportação brasileira.

Como delimitação da pesquisa, realizou-se a coleta das informações através da mineração no Portal Aliceweb dos códigos de Sistema Harmonizado 611241 - Biquínis e Maiôs de banho de malhas de fibras sintéticas, 611249 - Biquínis e Maiôs de banhos de malha de outros materiais têxteis e 621112 - Biquínis e Maiôs de banho exceto de malhas, sendo os dados disponibilizados em três fatores: peso líquido, quantidade e valores em US\$ FOB; com período de análise entre janeiro de 2005 a dezembro de 2009, agrupados, anualmente, por país, com acesso ao banco de dados realizado em janeiro de 2010.

\subsection{Análise dos critérios de desempenho dos países importadores ba- seado nas exportações brasileiras}

O mercado de moda praia brasileiro é composto, em sua maioria, de empresas de pequeno e médio porte, as quais apresentam uma dificuldade na busca de coleta e interpretação dos dados de mercado. O modelo proposto visa a reduzir esta lacuna através da elaboração de uma tabela que possibilita ao exportador uma análise preliminar do desempenho importador de um país do qual o Brasil já realiza suas exportações e demonstra qual a sua posição no mercado, o perfil comprador, a performance de compra, a sua tendência de preços e o valor agregado do produto em relação aos demais países.

Este estudo se baseia em dados oficiais quantitativos das exportações brasileiras, disponibilizados pelo Ministério de Desenvolvimento, Indústria e Comércio Exterior do Brasil. Após o tratamento estatístico e a elaboração de planilhas de cálculos, é possível elaborar uma tabela onde se demonstra o resultado do estudo. Para realizar a interpretação deste referido quadro, faz-se necessário o entendimento dos conceitos supraproposto, descritos a seguir:

a) posição no mercado: para determinar a posição no mercado, será realizada a classificação em ordem decrescente em relação à quantidade importada no último ano;

b) nome do país importador: a segunda coluna vem o nome oficial do país importador disponibilizado pelo Ministério do Desenvolvimento, Indústria e Comércio Exterior do Brasil;

c) quantidade ou peso exportado: neste campo, serão disponibilizadas as quantidades totais ou o peso total de produtos exportados no último ano. No caso da moda praia, será utilizada a quantidade total;

d) preço médio exportado: o preço médio exportado será encontrado realizando-se a divisão entre o volume total exportado em US\$ FOB no ano divido pela quantidade total de produtos exportados;

e) perfil comprador: para a análise de perfil comprador, é analisado se o país apresenta compras consecutivas durante cinco anos. Se neste período houver compras regulares em todos os anos, este país será considerado comprador habitual. Será considerado comprador eventual aquele que no período de cinco anos pelo menos em um ano não realizou a compra do produto;

f) Performance de compra: para definir a performance de compras, deve-se analisar separadamente os países de acordo com o seu perfil comprador. Para os países considerados compradores eventuais, serão considerados de performance potencial aqueles que pelo menos nos últimos três anos realizaram compras consecutivas e de performance indefinida aqueles países que no período dos últimos três anos pelo menos um ano não realizou compra. De acordo com FMI (apud LÉLIS; FRAGA; LIMA, 2009), a crise mundial que se verificou nos últimos 
anos afetou as projeções de crescimento das economias mundiais que variaram de $3 \%$ em outubro de 2008 para -1,3\% em abril de 2009. Segmentando esta projeção, verificou-se que, para as economias desenvolvidas, as taxas previstas para 2008 eram de $+0,5 \%$ passaram para $3,8 \%$, em 2009, e para os emergentes e em desenvolvimento estas taxas passaram de $6,1 \%$ em 2008 para 1,6\% em abril 2009. Para se definir a performance de compra dos países de perfil comprador habitual, levando-se em consideração as projeções de crescimento econômico mundial, estes serão classificados em três grupos: i) em crescimento: para os países que apresentarem taxas de crescimento da quantidade exportada de, no mínimo, superiores a 3\% em relação ao ano anterior; ii) estabilizado: para os países em que a taxa de crescimento não ultrapassar os 3\% e não obtiver queda da exportação no período de até -3\%; e iii) em declínio: aqueles países que apresentaram taxas negativas inferiores a $-3 \%$ em relação ao ano anterior;

g) tendência de preço: para definir a tendência de preços, serão considerados três grupos: i) aumento: para aqueles países que nos últimos três anos consecutivos apresentaram aumento médio dos preços; ii) variável: para aqueles cujos preços nos últimos três anos apresentaram aumentos e quedas de preços médio; iii) queda: para aqueles países que apresentarem nos últimos três anos consecutivos queda nos preços médios praticados; e iv) sem tendência: para aqueles países que em pelo menos um ano não efetuou compras;

h) valor agregado: para se determinar o valor agregado, levou-se em consideração, conforme Lapponi (2005), os valores ordenados crescentes das variáveis em quartis, possibilitando posicionar um determinado país relativamente ao ano analisado. Considerando-se os valores em US\$FOB que os produtos foram exportados no último ano, o país será classificado em três grupos: i) alto: quando o valor médio praticado pelo país ficar no 3 quartil da amostra; ii) médio: quando o valor médio ficar entre o $2^{\circ}$ e $3^{\circ}$ quartil; e iii) baixo: quando a média dos valores de venda ficaram abaixo do 2 o quartil.

\section{Apresentação e discussão dos resultados}

\subsection{Desempenho exportador brasileiro de têxteis e confeccionados}

A gênese do desempenho econômico do setor têxtil e de confecções está vinculada ao fato que essa indústria ainda é altamente intensiva de trabalho e, para um país como o Brasil, que necessita de empregabilidade para sua população, este setor é importante para a inserção social e criar condições para a melhoria da qualidade e da produtividade em padrões internacionais de competitividade. Com mais de 30 mil empresas distribuídas pelo país, classificadas desde microempresas familiares ou cooperativas de produção, algumas inclusive instaladas nas residências dos empreendedores, até grandes corporações empresariais das quais, de acordo com ABIT (2010), possibilitam juntas um faturamento anual de, aproximadamente, US\$ 24 biIhões e empregam mais de 1,65 milhões de pessoas.

Esse setor ainda pode ser caracterizado pelas dimensões de seu parque fabril: é a sexta maior indústria têxtil do mundo, o segundo maior produtor de denim e o terceiro na produção de malhas. Autossuficiente na produção de algodão, o Brasil produz 9,8 bilhões de peças de vestuário por ano, sendo referência mundial em beachwear, jeanswear e homewear. Apesar desses números significativos, a Agência Brasileira de Promoção de Exportação e Investimentos (APEXBRASIL, 2010), em conjunto com as entidades empresariais deste segmento industrial (ABIT, 2010) quer tornar o setor têxtil e de confecção brasileiro uma referência em tecnologia e inovação no cenário mundial, através do programa TexBrasil.

No ano de 2009, conforme segmentação estabelecida pela ABIT (2010), as exportações brasileiras de têxteis e de confeccionados representaram 1,24\% do volume exportado pelo 
Brasil, com a marca de US $\$ 1,89$ bilhões, apresentando uma queda de $-1,82 \%$ se comparado com os valores exportados no ano anterior. Realizando-se uma segmentação somente dos produtos confeccionados, estes apresentaram uma queda ainda mais significativa, na ordem de 31,45\%, com um volume exportado em 2009 de US $\$ 381,2$ milhões. Subdividindo-se este segmento em vestuário de malha, no qual estão incluídos os produtos de moda praia, apresentou uma queda de $-35,22 \%$, com um volume exportado de US\$92,5 milhões.

Os principais portos de exportação braseira de têxtil e de confeccionados em relação ao peso líquido transportado são os de: Santos: naval (50\%), Paranaguá: naval (14,8\%), Salvador: naval (7\%), Uruguaiana: rodoviário $(5,2 \%)$ e Foz do Iguaçu: rodoviário $(3,9 \%)$. Também se verificou que, em valores US \$ FOB, 82,9\% das exportações brasileira de têxteis e confeccionados são realizadas por sete estados: São Paulo (20,7\%), Mato Grosso (19,1), Bahia (16,1\%), Santa Catarina (9,3\%), Rio Grande do Sul $(6,7 \%)$, Paraná $(6,3)$ e Minas Gerais $(4,7 \%)$.

\subsection{O desempenho exportador brasileiro de moda praia}

Ao longo dos últimos cinco anos (de janeiro de 2005 até dezembro de 2009), o setor de moda praia brasileiro exportou um volume acumulado de 14.118 .608 peças de biquínis e maiôs, num total de US\$102,56 milhões FOB, em negócios realizados com 137 países ao longo deste período, dos quais, apenas 10 países representam um total de $73,3 \%$ da quantidade exportada: Estados Unidos (36,3\%), Portugal (11,8\%), Itália (9,1\%), Espanha $(7,4 \%)$, Chile $(5,7 \%)$, Argentina (3,1\%), Alemanha (2,4\%), Angola (2,1\%), França (2,0\%) e Países Baixos (1,8\%).

Neste período, verificou-se queda brusca e consecutiva das quantidades de produtos de moda praia exportada, sendo que, apenas no ano de 2006, a queda foi de $-38,8 \%$ em relação ao ano anterior e quedas consecutivas de -13\% em 2007, -42,4\% em 2008 e -11,7\% no ano de 2009.

Se considerados os valores em US\$ FOB pelos quais a moda praia brasileira foi exportada, conforme ilustra a tabela 1, verifica-se que, no período de 2005 a 2008, ocorriam aumentos consecutivos nos preços médios da moda praia exportada, passando de US\$ 9.81 para US\$ 19.92 e, em 2009, constata-se que o preço médio caiu para US\$19.55. Embora a mediana venha apresentando sinais de crescimento constante desde 2005, em nenhum momento ela ultrapassou a média, conforme Laponi (2005), a curva de distribuição das exportações de moda praia brasileira possui inclinação para a direita.

Tabela 1 - Média, mediana, quartil e desvio padrão em US\$ FOB das exportações de moda praia por ano

\begin{tabular}{lccccc} 
& 2005 & 2006 & 2007 & 2008 & 2009 \\
\hline 1o Quartil & 4,67 & 5,56 & 8,13 & 10,74 & 9,11 \\
\hline Mediana & 7,18 & 8,58 & 12,70 & 14,24 & 14,36 \\
3o Quartil & 11,17 & 14,50 & 17,53 & 21,15 & 23,49 \\
Média & 9,81 & 16,60 & 14,28 & 19,92 & 19,55 \\
Desvio Padrão & 10,05 & 40,85 & 9,10 & 18,91 & 16,88 \\
Coef. Variação & 1,02 & 2,46 & 0,64 & 0,95 & 0,86 \\
\hline
\end{tabular}

Fonte: calculado com dados da SECEX (2010). 
Analisando-se a tabela 1, verifica-se que não houve nenhum valor do coeficiente de variação abaixo de 0,30, significando que há uma heterogeneidade nos preços médios praticados entre os países. Isto demonstra que existe uma diversidade muito grande de tipos de produtos e mercados e que cada exportador deverá analisar separadamente o comportamento de preços em relação aos países onde atua.

No ano de 2009, as exportações brasileiras de moda praia ficaram concentradas em $79,7 \%$ da quantidade total exportadas em apenas três estados fabricantes, e os destaques foram: São Paulo (33,9\%), Rio de Janeiro (31,8\%) e Santa Catarina (13,9\%). Um fator interessante observado nos dados deste segmento foi a exportação realizada por consumo de bordo, ou seja, venda de moda praia brasileira diretamente no interior de navios turísticos internacionais, representando $0,8 \%$ da quantidade total exportada.

Realizando-se um filtro em relação aos meses em que ocorrem as exportações, verificase que, no primeiro trimestre do ano, foi exportado $49,6 \%$ e no segundo trimestre $33,7 \%$, o que significa que $83,3 \%$ do volume exportado de moda praia ocorre no primeiro semestre do ano, demonstrando que esta estratégia vem atender às necessidades de sazonalidade de produção doméstica, haja vista que a exportação da moda praia brasileira ocorre, principalmente, para países onde a temporada de verão é compreendida entre os meses de junho a agosto, inversamente à brasileira, que ocorre entre dezembro e fevereiro.

Em relação ao modal utilizado em 2009, para a exportação da moda praia brasileira, $78,9 \%$ da quantidade total foi enviada através do modal aéreo, sendo os principais aeroportos utilizados o de São Paulo (28,6\%), seguido do Rio de Janeiro (26,9\%) e de Campinas (12,5\%). Em relação aos demais modais, o naval participa com 19\%, sendo o Porto de Itajaí responsável por $10,2 \%$ e o Porto de Santos por 7,9\% da quantidade. O modal rodoviário representa 2,1\%.

\subsection{Resultado da análise quantitativa de desempenho dos países im- portadores de moda praia baseado no desempenho exportador brasileiro}

Após realizar a coleta e tabulação dos dados, estruturou-se a tabela 2, que ilustra o resultado do perfil dos 100 países importadores de moda praia no período delimitado de 2005 até 2009. Para verificar o perfil de cada país, devem-se analisar os dados de cada linha, em que, por exemplo, a Itália foi terceira maior compradora em 2009, com 216.767 peças, apresentando um preço médio US\$5.33 FOB, perfil comprador habitual, o que significa que esse país comprou de forma contínua nos últimos cinco anos, performance de compra crescente, o que significa que, nos últimos três anos houve crescimento contínuo da quantidade comprada, tendência de preços variável e valor agregado baixo. 
Tabela 2 - Perfil dos países compradores de moda praia baseado na exportação brasileira 2009

\begin{tabular}{|c|c|c|c|c|c|c|c|}
\hline $\begin{array}{l}\text { Posiç } \\
\text { ão } \\
2009\end{array}$ & $\begin{array}{c}\text { País } \\
\text { Importador }\end{array}$ & $\begin{array}{l}\text { Quantidade } \\
\text { exportada }\end{array}$ & $\begin{array}{l}\text { US\$ FOB } \\
\text { Médio }\end{array}$ & $\begin{array}{c}\text { Perfil } \\
\text { comprador }\end{array}$ & $\begin{array}{l}\text { Performance } \\
\text { de compra }\end{array}$ & $\begin{array}{l}\text { Tendência } \\
\text { de preço }\end{array}$ & $\begin{array}{c}\text { Valor } \\
\text { Agregado }\end{array}$ \\
\hline 1 & ESTADOS UNIDOS & 389540 & 7,75 & Habitual & Declínio & Variável & Baixo \\
\hline 2 & PORTUGAL & 293936 & 9,10 & Habitual & Estabilizado & Variável & Baixo \\
\hline 3 & ITÁLIA & 216767 & 5,33 & Habitual & Crescimento & Variável & Baixo \\
\hline 4 & ESPANHA & 82724 & 8,54 & Habitual & Estabilizado & Variável & Baixo \\
\hline 5 & ANGOLA & 61240 & 3,70 & Habitual & Crescimento & Aumento & Baixo \\
\hline 6 & FRANÇA & 37581 & 12,89 & Habitual & Crescimento & Variável & Médio \\
\hline 7 & GRÉCIA & 32449 & 12,56 & Habitual & Estabilizado & Variável & Médio \\
\hline 8 & CUBA & 28848 & 5,02 & Eventual & Indefinida & Sem Tendência & Baixo \\
\hline 9 & ALEMANHA & 27879 & 10,06 & Habitual & Crescimento & Variável & Médio \\
\hline 10 & JAPÃO & 18319 & 19,46 & Habitual & Estabilizado & Variável & Médio \\
\hline 11 & VENEZUELA & 18054 & 9,66 & Habitual & Declínio & Variável & Médio \\
\hline 12 & CANADÁ & 17182 & 9,34 & Habitual & Estabilizado & Variável & Médio \\
\hline 13 & ARGENTINA & 16110 & 9,15 & Habitual & Declínio & Variável & Médio \\
\hline 14 & URUGUAI & 14943 & 6,98 & Habitual & Estabilizado & Aumento & Baixo \\
\hline 15 & CHILE & 12298 & 14,21 & Habitual & Crescimento & Aumento & Médio \\
\hline 16 & ISRAEL & 12150 & 16,96 & Habitual & Crescimento & Variável & Médio \\
\hline 17 & REINO UNIDO & 11487 & 19,08 & Habitual & Declínio & Variável & Médio \\
\hline 18 & PANAMÁ & 10871 & 15,04 & Habitual & Declínio & Aumento & Médio \\
\hline 19 & PARAGUAI & 9824 & 11,70 & Habitual & Crescimento & Variável & Médio \\
\hline 20 & EMIRADOS ÁRABES UNIDOS & 7854 & 23,47 & Habitual & Estabilizado & Variável & Médio \\
\hline 21 & COSTA RICA & 7310 & 16,43 & Habitual & Estabilizado & Aumento & Médio \\
\hline 22 & MOÇAMBIQUE & 6533 & 3,43 & Eventual & Potencial & Variável & Baixo \\
\hline 23 & AUSTRÁLIA & 4665 & 9,09 & Habitual & Estabilizado & Variável & Baixo \\
\hline 24 & MARTINICA & 4417 & 7,37 & Habitual & Estabilizado & Queda & Baixo \\
\hline 25 & MÉXICO & 4351 & 13,62 & Habitual & Declínio & Variável & Médio \\
\hline 26 & SUÍÇA & 4170 & 12,01 & Habitual & Declínio & Variável & Médio \\
\hline 27 & GUADALUPE & 3974 & 14,38 & Habitual & Estabilizado & Variável & Médio \\
\hline 28 & ANTILHAS HOLANDESAS & 3960 & 21,82 & Habitual & Estabilizado & Variável & Médio \\
\hline 29 & CANÁRIAS, ILHAS & 3951 & 12,17 & Habitual & Crescimento & Variável & Médio \\
\hline 30 & PAIISES BAIXOS (HOLANDA) & 3360 & 17,22 & Habitual & Declínio & Variável & Médio \\
\hline 31 & BOLÍVIA & 2996 & 10,77 & Habitual & Crescimento & Aumento & Médio \\
\hline 32 & SUÉCIA & 2788 & 14,61 & Habitual & Estabilizado & Variável & Médio \\
\hline 33 & PERU & 2784 & 11,19 & Habitual & Estabilizado & Variável & Médio \\
\hline 34 & LIBANO & 2688 & 35,32 & Habitual & Estabilizado & Variável & Alto \\
\hline 35 & CINGAPURA & 2683 & 26,61 & Habitual & Declínio & Variável & Alto \\
\hline 36 & SAN MARINO & 2245 & 5,38 & Eventual & Potencial & Queda & Baixo \\
\hline 37 & CROACIA & 1866 & 19,05 & Habitual & Crescimento & Aumento & Médio \\
\hline 38 & TRINIDAD E TOBAGO & 1699 & 14,36 & Habitual & Crescimento & Variável & Médio \\
\hline 39 & TURQUIA & 1471 & 40,48 & Habitual & Crescimento & Variável & Alto \\
\hline 40 & REPÚBLICA DOMINICANA & 1458 & 9,90 & Habitual & Estabilizado & Variável & Médio \\
\hline 41 & MALÁSIA & 1077 & 21,57 & Eventual & Potencial & Variável & Médio \\
\hline 42 & COLÔMBIA & 993 & 12,87 & Habitual & Estabilizado & Queda & Médio \\
\hline 43 & RÚSSIA, FEDERAÇÃO DA & 895 & 16,61 & Habitual & Estabilizado & Variável & Médio \\
\hline 44 & CORÉIA, REPÚBLICA DA (SUL) & 863 & 15,19 & Eventual & Indefinida & Sem Tendência & Médio \\
\hline
\end{tabular}




\begin{tabular}{|c|c|c|c|c|c|c|c|}
\hline 45 & NORUEGA & 861 & 6,85 & Habitual & Estabilizado & Queda & Baixo \\
\hline 46 & ÁFRICA DO SUL & 851 & 16,25 & Habitual & Declínio & Aumento & Médio \\
\hline 47 & PORTO RICO & 773 & 23,44 & Habitual & Estabilizado & Aumento & Médio \\
\hline 48 & MAURÍCIO & 606 & 32,21 & Eventual & Indefinida & Aumento & Alto \\
\hline 49 & HONG KONG & 567 & 31,51 & Habitual & Declínio & Aumento & Alto \\
\hline 50 & ARÁBIA SAUDITA & 526 & 35,66 & Habitual & Estabilizado & Aumento & Alto \\
\hline 51 & NOVA ZELÂNDIA & 465 & 7,21 & Habitual & Estabilizado & Variável & Baixo \\
\hline 52 & SURINAME & 391 & 6,27 & Habitual & Declínio & Variável & Baixo \\
\hline 53 & BÉLGICA & 379 & 5,42 & Habitual & Declínio & Variável & Baixo \\
\hline 54 & NAMÍBIA & 378 & 3,13 & Eventual & Indefinida & Sem Tendência & Baixo \\
\hline 55 & ESLOVÊNIA & 372 & 6,37 & Eventual & Potencial & Queda & Baixo \\
\hline 56 & BARBADOS & 342 & 36,94 & Habitual & Crescimento & Variável & Alto \\
\hline 57 & POLINÉSIA FRANCESA & 336 & 8,55 & Habitual & Declínio & Aumento & Baixo \\
\hline 58 & GUATEMALA & 327 & 9,91 & Habitual & Crescimento & Variável & Médio \\
\hline 59 & MARROCOS & 324 & 22,06 & Eventual & Potencial & Variável & Médio \\
\hline 60 & EL SALVADOR & 311 & 10,30 & Eventual & Indefinida & Variável & Médio \\
\hline 61 & FILIPINAS & 294 & 5,20 & Habitual & Declínio & Variável & Baixo \\
\hline 62 & ARUBA & 246 & 18,88 & Habitual & Declínio & Aumento & Médio \\
\hline 63 & CAYMAN, ILHAS & 232 & 5,64 & Eventual & Indefinida & Sem Tendência & Baixo \\
\hline 64 & MALTA & 214 & 10,72 & Eventual & Indefinida & Sem Tendência & Médio \\
\hline 65 & BAHREIN & 200 & 65,00 & Eventual & Indefinida & Sem Tendência & Alto \\
\hline 66 & JAMAICA & 172 & 15,46 & Eventual & Potencial & Variável & Médio \\
\hline 67 & EGITO & 170 & 24,98 & Habitual & Declínio & Aumento & Alto \\
\hline 68 & ANTIGUA E BARBUDA & 164 & 9,32 & Eventual & Indefinida & Aumento & Médio \\
\hline 69 & CHIPRE & 162 & 23,50 & Habitual & Declínio & Variável & Alto \\
\hline 70 & ROMÊNIA & 155 & 14,36 & Eventual & Indefinida & Sem Tendência & Médio \\
\hline 71 & IRLANDA & 150 & 6,20 & Habitual & Crescimento & Variável & Baixo \\
\hline 72 & NICARÁGUA & 139 & 22,64 & Eventual & Potencial & Variável & Médio \\
\hline 73 & REUNIÃO & 134 & 31,42 & Habitual & Crescimento & Aumento & Alto \\
\hline 74 & TCHECA, REPÚBLICA & 132 & 6,57 & Eventual & Potencial & Queda & Baixo \\
\hline 75 & HONDURAS & 131 & 11,92 & Eventual & Potencial & Variável & Médio \\
\hline 76 & SENEGAL & 118 & 18,78 & Eventual & Indefinida & Aumento & Médio \\
\hline 77 & HAITI & 108 & 33,86 & Habitual & Declínio & Variável & Alto \\
\hline 78 & CHINA & 90 & 20,91 & Eventual & Potencial & Variável & Médio \\
\hline 79 & SEYCHELLES & 81 & 11,00 & Eventual & Indefinida & Sem Tendência & Médio \\
\hline 80 & FINLÂNDIA & 77 & 11,34 & Habitual & Declínio & Queda & Médio \\
\hline 81 & SÃO TOMÉ E PRÍNCIPE & 77 & 21,53 & Eventual & Indefinida & Sem Tendência & Médio \\
\hline 82 & QUIRGUIZ, REPÚBLICA & 69 & 11,99 & Eventual & Indefinida & Sem Tendência & Médio \\
\hline 83 & GUIANA FRANCESA & 66 & 48,76 & Habitual & Estabilizado & Aumento & Alto \\
\hline 84 & ÍNDIA & 66 & 75,65 & Eventual & Potencial & Aumento & Alto \\
\hline 85 & ÁUSTRIA & 62 & 31,32 & Habitual & Declínio & Variável & Alto \\
\hline 86 & DINAMARCA & 52 & 11,75 & Habitual & Declínio & Variável & Médio \\
\hline 87 & ESLOVACA, REPÚBLICA & 51 & 26,61 & Eventual & Potencial & Queda & Alto \\
\hline 88 & MALI & 48 & 27,56 & Eventual & Indefinida & Aumento & Alto \\
\hline 89 & TAIWAN (FORMOSA) & 34 & 5,91 & Habitual & Crescimento & Variável & Baixo \\
\hline 90 & GRANADA & 33 & 4,00 & Eventual & Indefinida & Variável & Baixo \\
\hline
\end{tabular}




\begin{tabular}{|llcccccc}
91 & TURCAS E CAICOS, ILHAS & 31 & 71,52 & Eventual & Indefinida & Sem Tendência & Alto \\
\hline 92 & HUNGRIA & 29 & 20,59 & Habitual & Declínio & Variável & Médio \\
\hline 93 & EQUADOR & 21 & 5,57 & Habitual & Declínio & Variável & Baixo \\
\hline 94 & MALDIVAS & 16 & 90,38 & Eventual & Potencial & Variável & Alto \\
\hline 95 & CATAR & 12 & 86,33 & Eventual & Indefinida & Variável & Alto \\
\hline 96 & ISLÂNDIA & 12 & 7,00 & Habitual & Declínio & Queda & Baixo \\
\hline 97 & CANAL, ILHAS DO & 7 & 33,29 & Eventual & Indefinida & Sem Tendência & Alto \\
\hline 98 & BERMUDAS & 4 & 27,75 & Eventual & Indefinida & Sem Tendência & Alto \\
\hline 99 & NOVA CALEDÔNIA & 4 & 33,75 & Habitual & Declínio & Aumento & Alto \\
\hline 100 & INDONÉSIA & 2 & 49,50 & Habitual & Declínio & Sem Tendência & Alto \\
\hline
\end{tabular}

Fonte: calculado com dados da SECEX (2010).

\section{Conclusão}

Analisando-se os resultados apresentados, pode-se perceber que, no período proposto pela pesquisa, compreendido entre 2005 e 2009, verificou-se índices negativos de crescimento em relação à quantidade de produtos exportados de moda praia, sendo que apenas no ano de 2006 a queda foi de $-38,8 \%$ em relação ao ano anterior, que serviu de ano-base para esta pesquisa, e quedas consecutivas de -13\% em 2007, -42,4\% em 2008 e -11,7\% no ano de 2009.

Outro fato observado é a concentração dos países importadores, em que os 10 principais compradores do período total da pesquisa totalizaram $83,2 \%$ do volume comprado, destacando-se: Estados Unidos (39,6\%), Portugal (13,1\%), Itália (10,7\%), Espanha (7,1\%), Chile (3,3\%), Angola (2,4\%), Argentina (2,3\%), Grécia (1,6\%), Venezuela e Alemanha (1,5\% cada) e que alguns deles não se configuram na lista, ilustrada na tabela 2, dos 10 primeiros compradores de 2009 como o Chile, a Argentina e a Venezuela e em seus lugares pode-se verificar a França, Cuba e Japão.

O estudo mostrou que entre os 10 principais importadores de moda praia feminina em 2009, todos os demais apresentam perfil comprador habitual, exceto Cuba, em relação a sua performance, um país está em declínio, quatro com mercado estabilizado, outros quatro em crescimento e um indefinido. Em relação à tendência de preço, oito países possuem perfil variável, um em aumento e outro sem tendência e sobre o valor agregado, seis países apresentam-se como baixo, sendo que, destes, os cinco principais compradores e os demais, médio. Verificou-se, ainda, que entre os dez primeiros compradores nenhum possuía valor agregado alto.

Em suma, considerando-se que o objetivo deste estudo era estruturar uma tabela que possibilitasse aos empreendedores uma visão preliminar do desempenho dos países importadores de moda praia feminina, com base em dados quantitativos secundários, e os resultados, posteriormente obtidos, calculados e classificados, pode-se considerar que o objetivo deste estudo foi plenamente atingido.

É importante destacar que este trabalho não é um estudo conclusivo sobre o tema e que o empreendedor deverá realizar outras ações de pesquisa e estudo de mercados antes de ingressar no mercado externo. Desta forma, IEL-FIEMG (2008) sugere que o exportador participe de feiras e missões comerciais com o objetivo de realizar a venda de seus produtos, de eventos e missões técnicas em que poderá demonstrar seus produtos, ver as lacunas e oportunidades de melhoria de seus produtos e serviços, conhecer o que os outros concorrentes estão realizando e, mediante essas observações, incorporar inovações que lhe possam propiciar um diferencial no mercado. 


\section{Referências}

ABIT. Associação Brasileira da Indústria Têxtil e de Confecção. Disponível em: <http: // www.abit.org.br>. Acesso em: 13 jan. 2010.

APRENDENDO A EXPORTAR. Confecções. Disponível em: <http://www.aprendendoaexportar.gov.br/ confeccoes>. Acesso em: 04 jan. 2010.

BESSANT, J.; TID, J. Inovação e empreendedorismo. Trad. Elizamari Rodrigues Becker, Gabriela Perizzolo, Patrícia Lessa Flores da Cunha. Porto Alegre: Bookman, 2009.

BORIELO, S. Ondas de luxo. Revista Costura Perfeita, ano XI, n.53, p. 22-26, jan./fev. 2010.

CASTRO, J. M.; ABREU, P. G. F. Influência da inteligência competitiva em processos decisórios no ciclo de vida das organizações. Ciência da Informação, v. 35, n. 3, p. 15-29, set./dez. 2006.

DA ROCHA, A.; DE MELO, R. C. Internacionalização das micro e pequenas empresas: casos sobre internacionalização de empresas. Rio de Janeiro: SEBRAE, 2006.

FARO, R.; FARO, F. Curso de comércio exterior: visão e experiência brasileira. São Paulo: Atlas, 2007.

FEGHALI, M. K.; DWYER, D. As engrenagens da moda. Rio de Janeiro: Senac Rio, 2004.

FERREIRA, P. S.; MOREIRA, D. A. A inteligência competitiva no contexto de uma amostra de grandes companhias brasileiras. In: Anais do SIMPOI. São Paulo: FGVSP, 2008. CD-ROM.

GARCIA, C. O biquíni: uma verdadeira bomba. Disponível em: < http://almanaque.folha.uol.com.br/ biquini.htm>. Acesso em: 17 fev. 2010.

GARRIDO, I. Orientação para o mercado externo: o refinamento de uma escala de mensuração. Revista de Administração de Empresas, v. 47, n.4, p. 116-130, out./dez. 2007.

GOMES, E.; BRAGA, F. Inteligência competitiva: como transformar informação em um negócio lucrativo. Rio de Janeiro: Campus, 2001.
GUEDES, A. L. Negócios internacionais: estratégias de investimentos no contexto luso-brasileiro. Revista Comportamento Organizacional e Gestão, v. 14, n. 1, p. 29-43, 2008.

IEL-FIEMG. Federação das Indústrias do Estado de Minas Gerais. Anais do encontro de inovação e desenvolvimento regional da indústria mineira experiências e melhores práticas. Belo Horizonte: IEL-FIEMG, 2008.

INSTITUTO INOVAÇÃO. A inovação: conceitos, a importância de inovar, a dinâmica da inovação. Disponível em: <http://www.institutoinovacao.com.br/ inovacao.php>. Acesso em: 07 abr. 2008.

KHAUAJA, D. M. R.; HEMZO, M. A. Marca Brasil: ficção ou realidade? Uma análise das iniciativas da APEX-Brasil para a construção da marca Brasil. INTERNEXT - Revista Eletrônica de Negócios Internacionais da ESPM, São Paulo, v. 2, n. 1, p.7596, jan./jun. 2007.

LAPPONI , J. C. Estatística usando Excel. 7. ed. Rio de Janeiro: Elsevier, 2005.

LÉLIS, M.; FRAGA, K.; LIMA, M. Impactos da crise econômica sobre as exportações brasileiras: uma medida das perdas reais do primeiro semestre de 2009. Análise Apex-Brasil - Conjuntura \& Estratégia. Apex-Brasil, julho 2009.

LINDON, D. et al. Mercator 2000: teoria e prática do marketing. Lisboa: Publicações Dom Quixote, 2000.

MAFFINI GOMES, C.; KRUGLIANSKAS, I. Indicadores e características da gestão de fontes externas de informação tecnológica e do desempenho inovador de empresas brasileiras. Revista de Administração Contemporânea (RAC), v. 13, n.2, p.172188, abr./jun. 2009. Disponível em: <http:// redalyc.ua e mex.mx/s rc/in icio/ ArtPdfRed.jsp?iCve $=84011273002>$ ISSN 14156555. Acesso em: 10 jul. 2010.

MAIA, J. de M. Economia internacional e comércio exterior. 12 ed. São Paulo: Atlas, 2008.

MANEQUIM. A história do biquíni. Disponível em: $<$ http://manequim.abril.com.br/moda/historia-damoda $>$. Acesso em: 17 fev. 2010. 
MARQUES, C.T. Potencialidades e limitações da aplicação simultânea de aromas e de pigmentos sensíveis ao calor e à luz em artigos de moda praia. 2004. Disponível em: <http:// repositorium.sdum.uminho.pt/handle/1822/899>. Acesso em: 09 jul. 2010.

MILLER, J. P. O milênio da inteligência competitiva. Porto Alegre: Bookman, 2002.

NEVES, Jorge. Manual de estamparia têxtil. Guimarães: Escola de Engenharia

Universidade do Minho, 2000.

NICOLSKY, R. Fábrica de novidades: empresas investem em idéias inovadoras, 24/09/2007. 2007‥ Disponível em: < http://www.protec.org.br/ noticias.asp?cod=595 > . Acesso em: 29 jan. 2008.

NICOLSKY, R. Imitando é que se aprende. 27/7/ 2006. Disponível em: <http://www.protec.org.br/ artigos.asp?cod=56>. Acesso em: 29 jan. 2008.

OLIVEIRA, S. R. G. Consórcio de exportação de pequenas e médias empresas em moda praia localizadas em arranjos produtivos locais: aprendizado e resultados mercadológicos. 2006. 184 f. Tese (Doutorado em Administração de Empresas)Escola de Administração de Empresas de São Paulo - Fundação Getúlio Vargas, São Paulo, 2006.

SECEX. Secretaria de Comércio Exterior. Estatísticas das exportações brasileiras. Ministério do Desenvolvimento, Indústria e Comércio Exterior, Brasília, 2010. Disponível em: <http:// aliceweb.desenvolvimento.gov.br>. Acesso em: 20 jan. 2010.

SEVERINO, A. J. Metodologia do trabalho científico. 22. ed. São Paulo: Cortez, 2002.

STEVENSON, W. J. Estatística aplicada à Administração. Trad. Alfredo Alves de Farias. São Paulo: Harper \& Row do Brasil, 1981.

VAZQUEZ, J. L. Comércio exterior brasileiro. 8. ed. São Paulo: Atlas, 2007. 